\title{
Primeiros Socorros Nas Escolas: Uma Revisão Integrativa
}

\author{
Julianne Silva Garcia de Moura-Centro Universitário Estácio daAmazônia-Brasil ${ }^{1}$ \\ Ligiane Beatriz Mendes da Costa Centro Universitário Estácio daAmazônia-Brasil ${ }^{2}$ \\ Helenira Macedo Barros Machado Centro Universitário Estácio daAmazônia-Brasil ${ }^{3}$ \\ Eliana da Silva Coelho Mendonça Centro Universitário Estácio daAmazônia-Brasil ${ }^{4}$ \\ Cleiry Simone Moreira da Silva Centro Universitário Estácio daAmazônia-Brasil ${ }^{5}$
}

\begin{abstract}
Resumo
\footnotetext{
${ }^{1}$ e-mail: juliannegarcia83@gmail.com

2 e-mail: ligianemendees@gmail.com.

3 e-mail: helenira.barros@estacio.br

${ }^{4}$ e-mail: eliana.mendonca@ifrr.edu.br

s e-mail: cleiry.silva@estacio.br.
}

Segundo o Ministério da Saúde o atendimento de primeiros socorros pode ser realizado por qualquer pessoa que tenha conhecimento das técnicas básicas. Objetivo: Averiguar a importância da orientação de técnicas de primeiros socorros. Metodologia: trata-se da revisão integrativa, nas bases de dados BVS (Biblioteca Virtual em Saúde - Brasil) e LILACS (Literatura Latino-Americana do Caribe em Ciências da Saúde), utilizando os critérios de exclusão por descritores, título, idioma e ano de publicação. Resultado: a necessidade do ensino de primeiros socorros para profissionais de escolas públicas, pois estes são fatores determinantes na redução de acidentes, morbimortalidade, redução de danos, assim como precursor de promoção e prevenção da saúde, trazendo somente benefícios para as unidades que recebem este tipo de capacitação.

Palavra-chave: Primeiros socorros. Ensino. Acidentes. 


\section{INTRODUÇÃO}

Preparar a população para a realização dos primeiros socorros é fundamental, em especial no âmbito escolar, para atuação de forma correta na prestação de técnicas de socorro.

Primeiros socorros é uma pauta que ainda é pouco explorada e valorizada pela grande maioria da população. Ainda assim, afirma-se que o acidente é um evento não intencional capaz de causar lesões físicas ou emocionais, dependendo de sua gravidade, podendo ocorrer em quaisquer ambientes (RODRIGUES; RODRIGUES, 2016).

O ambiente escolar, se configura como cenário importante para ocorrência de incidentes que necessitem de técnicas de Primeiros Socorros. Quando falamos de crianças, sabe-se que as mesmas passam pelo menos um terço do seu cotidiano dentro da escola, trazendo assim para este momento um dos maiores índices de acidentes ocorridos entre as idades de 01 (um) a 14 (quatorze anos), tendo como consequências dessa incidência desde traumas leves e sem a necessidade de intervenções até óbitos infantis (RODRIGUES, RODRIGUES, 2016).

Em casos de riscos moderados e graves um socorro imediato é de extrema importância e decisivo no quadro do paciente, podendo tender entre a vida e morte deste. Sabemos a Lei Lucas (Lei $\mathrm{n}^{\mathrm{o}}$ 13.722) foi sancionada em 04 de outubro de 2018, e torna obrigatória a capacitação em noções básicas de primeiros socorros de professores e funcionários de estabelecimentos de ensino públicos e privados de educação básica e de estabelecimentos de recreação infantil.

De acordo com Silva et al. (2018) o ambiente escolar surge como um local de alerta para a ocorrência de situações de urgência e emergência, sendo os alunos possíveis vítimas e os professores prováveis testemunhas desses incidentes, o que os tornam peças-chave para intervir nesses eventos, diminuindo complicações e melhorando o prognóstico.

Segundo Macedo (2008), a teórica da enfermagem, Florence Nightingale, destaca as interferências e condições do ambiente que afetam a vida e o funcionamento do organismo, que podem auxiliar na prevenção de doenças ou contribuir para a morte. Florence, em suas anotações, mencionou os elementos ambientais que devem ser ajustados e controlados para restaurar a saúde do paciente: ar puro, clareza, limpeza, aquecimento, sossego, intervenção no momento adequado e alimentação adequada.

A segurança no espaço escolar, principalmente no que tange ao ambiente físico, social e psicológico, deve ser objeto de constante preocupação dos responsáveis, dos professores e da direção escolar. A inquietude e a imprevisão inerentes à infância tornam a criança suscetível aos riscos e, às vezes, o educador não sabe lidar com essas adversidades. As crianças possuem características que predispõem ao acontecimento de lesões na escola, tais como os variados 
níveis de desenvolvimento cognitivo e motor, a curiosidade de explorar situações desconhecidas para as quais não possui preparo físico, a agressividade e intensidade das atividades recreativas, a exposição a comportamentos de risco e as atitudes de desafios às regras institucionais (LIBERAL, et al, 2005).

Estudos revelam que os acidentes envolvendo o público infantil, geralmente, acometem cabeça, face e membros, e são associados às quedas, cortes e fraturas. Estudo realizado na França, com a participação de 2396 crianças e adolescentes que sofreram acidentes na escola e foram atendidas na enfermaria escolar, mostrou que 52,8\% dos agravos ocorreram durante atividades relacionadas à prática esportiva e 12,7\% durante a prática de atividades recreativas. A análise dos resultados permitiu observar que, segundo os alunos acidentados, o descuido pessoal foi responsável por $26 \%$ dos acidentes e a falta de estabilidade por $17,5 \%$. As hospitalizações precisaram ocorrer em $2,7 \%$ dos casos e o afastamento da escola sem internação hospitalar ocorreu em 11,4\% dos casos (PRÉDINE et al. apud CARMO, ARAÚJO \& FRANCISCO, 2007).

Salientamos que, com o déficit no conhecimento acerca de primeiros socorros por parte de alunos e funcionários, e com a Lei Lucas (Lei $n^{\circ}$ 13.722) não tendo aplicabilidade (implementação) dentro das escolas de estados e município no território brasileiro. Tendo em vista a incidência crescente dos traumas e das complicações inerentes a ele, torna-se de suma importância que sejam discutidos e ensinados métodos de prevenção e de atendimento nas escolas de nível fundamental, e onde constituem-se ambientes de construção de processo dinâmico e continuidade para sua aplicação, tornando-se necessário que se inicie desde cedo.

A ideia de existir o ensino de primeiros socorros dentro das escolas públicas ainda é pouco estudada e ainda menos aplicada. Porém, não são necessários grandes esforços em busca de dados para entender a sua necessidade com certa urgência, professores, alunos e os demais colaboradores das instituições de ensino, possuem um conhecimento quase que irrelevante sobre o tema em questão. Portanto, a pesquisa objetivou averiguar a importância da orientação de técnicas de primeiros socorros e propor um produto educativo sobre as informações de primeiros socorros para as crianças e adolescentes como medida de prevenção.

\section{PROCEDIMENTO METODOLÓGICO}

Este estudo trata-se de uma revisão integrativa de literatura, realizada com base em artigos científicos, que estão disponíveis nos bancos de dados: BVS (Biblioteca Virtual em Saúde- Brasil) e LILACS (Literatura Latino-Americana do Caribe em Ciências da Saúde). 
Utilizamos como critério de inclusão para extração dos dados: a identificação do artigo (título, base de dados, autores, idioma e ano de publicação); o tipo de publicação (enfermagem, outra); e as características metodológicas do estudo (Tipo de pesquisa, objetivo, amostra, tratamento dos dados, intervenções, resultados, análise, nível de evidência) com as seguintes palavras-chave: "Primeiros socorros nas escolas", "Ensino de primeiros socorros" e "Acidentes nas escolas". Os resultados das buscas foram de aproximadamente duzentos e vinte e seis (226) artigos publicados, dos quais oito (8) deles foram selecionados entre os anos de 2017 a 2020, para as conclusões de resultados desta revisão.

Para a análise compreensiva dos discursos apresentados pelos participantes Bardin (1977), ressalta que o pesquisador primeiramente deve ficar atento aos momentos de aproximação e numa postura de abertura para vivência do outro, para isso é preciso que a pesquisa suspenda seu juízo de valor e o segundo passo o distanciamento reflexivo sobre aquela compreensão intuitiva quando pretende captar e descrever o sentido da vivência dos pesquisados.

Contudo, para contribuir ainda mais com o método, neste estudo, foi utilizada a análise lexicográfica, que por sua vez, irá determinar, quantitativamente, a ocorrência de palavras com a frequência absoluta, porcentual, chi ${ }^{2}$ e grau de significância ou P(significância), palavras (unidades lexicais) que serão listadas a partir do processamento das respostas dos participantes da pesquisa, com a ajuda do software Iramuteq 7.2 (LAHLOU, 2012; RATINAUD \& MARCHAND, 2012).

Foram produzidas tabelas, permitindo a avaliação das informações coletadas e a realização de discussões e análises. Vejamos:

Quadro 1- Procedimento de seleção dos artigos incluídos na revisão.

\begin{tabular}{|l|c|c|}
\hline \multicolumn{2}{|c|}{ PROCEDIMENTO METODÓLOGICO } \\
\hline Bancos de dados & \multicolumn{1}{|c|}{ BVS } & LILACS \\
\hline Descritores: & $\begin{array}{l}\text { "Primeiros socorros nas escolas" } \\
\text { "Ensino de primeiros socorros" } \\
\text { "acidentes nas escolas" }\end{array}$ & $\begin{array}{l}\text { "Primeiros socorros nas escolas" } \\
\text { "Eno de primeiros socorros" } \\
\text { "acidentes nas escolas" }\end{array}$ \\
\hline Tipo de trabalho: Artigo & 133 & 93 \\
\hline Abordagem: qualitativa & 16 & 41 \\
\hline Idioma: português & 39 & 4 \\
\hline $\begin{array}{l}\text { Ano de publicação: } \\
\text { 2017 a 2021 }\end{array}$ & 39 & 2 \\
\hline Amostra final & 6 & \\
\hline
\end{tabular}

Fonte: Esquematizado pelos autores 


\section{RESULTADOS E DISCURSÃO}

Temos na Tabela I a divisão dos dados principais de cada artigo. A identificação do estudo, nome dos autores, título, ano de publicação e a revista. Já na Tabela II temos destacados o delineamento e método, objetivos e resultados de cada estudo. Encontramos 226 estudos, dos quais apenas 08 referiam-se ao tema apresentado, então foram selecionados para compor este estudo (Quadro II).

A respeito aos periódicos dos artigos selecionados, um foi encontrado com destaque: quanto ao ano de publicação dos artigos selecionados 3 foram publicados no ano de 2017, 1 no ano de 2018, 1 no ano de 2019 e 3 no ano de 2020, totalizando assim, os 08 artigos encontrados, identificados em ordem cronológica: A1, A2, A3, A4, A5, A6, A7 e A8. Vejamos:

Quadro II - Distribuição dos estudos incluídos segundo os autores, título do estudo, ano de publicação e o nome da revista.

\begin{tabular}{|c|c|c|c|c|}
\hline Estudo/autores & Título & Objetivo & Ano & Revista \\
\hline $\begin{array}{l}\text { A1 } \\
\text { Silva DP da, Nunes } \\
\text { JBB, Moreira RTF et } \\
\text { al. }\end{array}$ & $\begin{array}{l}\text { Primeiros socorros: Objeto } \\
\text { de educação em saúde para } \\
\text { professores }\end{array}$ & $\begin{array}{lr}\text { Avaliar o impacto do } \\
\text { ensino de } \\
\text { socorros } & \text { primeiros } \\
\text { conhecimento } & \text { no } \\
\text { habilidade } & \text { de } \\
\text { professores. } & \end{array}$ & 2018 & $\begin{array}{l}\text { Revista de } \\
\text { Enfermagem } \\
\text {-UFPE }\end{array}$ \\
\hline $\begin{array}{l}\text { A2 } \\
\text { Faria, W.A.; B.F.F.; } \\
\text { Silva, M.A.; Santos, } \\
\text { R.C.; Pena, H.P. }\end{array}$ & $\begin{array}{lrr}\text { Primeiros } & \text { socorros para } \\
\text { professores } & \text { em } & \text { âmbito } \\
\text { escolar: } & & \text { Revisão } \\
\text { integrativa } & & \end{array}$ & $\begin{array}{l}\text { Evidenciar a importância } \\
\text { de primeiros socorros nas } \\
\text { escolas. }\end{array}$ & 2020 & $\begin{array}{l}\text { Revista } \\
\text { Nursing }\end{array}$ \\
\hline \begin{tabular}{l}
\multicolumn{1}{c}{$\mathbf{A 3}$} \\
Souza, M.F.; Divino, \\
A.B.; Souza, D.A.S.; \\
Cunha, $\quad$ S.G.S.; \\
Almeida, C.S.
\end{tabular} & $\begin{array}{l}\text { Conhecimento } r \\
\text { educadores dos } \\
\text { municipais de } \\
\text { infantil soducação } \\
\text { socorros }\end{array}$ & $\begin{array}{l}\text { Compreender } \\
\text { conhecimento dos } \\
\text { professores dos } \\
\text { de Educação Infantil } \\
\text { sobre Primeiros Socorros } \\
\text { referentes a crianças de } 3 \\
\text { a } 5 \text { anos. }\end{array}$ & 2020 & $\begin{array}{l}\text { Revista } \\
\text { Nursing }\end{array}$ \\
\hline \begin{tabular}{l}
\multicolumn{1}{c}{ A4 } \\
Mesquita,TM; \\
Albuquerque,RS; \\
Bomfim, AMA; \\
Sales, MLH; Santana, \\
MCCP; Ferreira, \\
AMV.
\end{tabular} & $\begin{array}{lr}\text { Recurso } & \text { educativo } \\
\text { primeiros } & \text { socorros no } \\
\text { processo } & \text { ensino- } \\
\text { aprendizagem em crianças } \\
\text { de uma escola pública }\end{array}$ & $\begin{array}{l}\text { Avaliar a efetividade de } \\
\text { uma estratégia de ensino- } \\
\text { aprendizagem baseada } \\
\text { em um recurso educativo } \\
\text { para identificação de } \\
\text { procedimentos de } \\
\text { primeiros socorros em }\end{array}$ & 2017 & $\begin{array}{l}\text { Revista } \\
\text { Ciência } \\
\text { Plural }\end{array}$ \\
\hline
\end{tabular}




\begin{tabular}{|c|c|c|c|c|}
\hline & & $\begin{array}{l}\text { alunos do ensino } \\
\text { fundamental de uma } \\
\text { escola pública. }\end{array}$ & & \\
\hline $\begin{array}{l}\text { A5 } \\
\text { Brito, JG; Silva, IM } \\
\text { da Godoy CB de, } \\
\text { França AP dos SJM. }\end{array}$ & $\begin{array}{l}\text { Avaliação de treinamento } \\
\text { sobre primeiros socorros } \\
\text { para equipe técnica de } \\
\text { escolas de ensino } \\
\text { especializado }\end{array}$ & $\begin{array}{l}\text { Analisar o efeito de } \\
\text { atividade educativa sobre } \\
\text { primeiros socorros em } \\
\text { acidentes escolares. }\end{array}$ & 2019 & $\begin{array}{c}\text { Cogitare } \\
\text { Enfermagem }\end{array}$ \\
\hline \begin{tabular}{lr}
\multicolumn{2}{c}{ A6 } \\
Neto, NMG; Caetano, \\
JA; Barros, LM; \\
Silva, \\
Vasconcelos; \\
\multicolumn{2}{c}{ EMR. }
\end{tabular} & $\begin{array}{lcr}\text { Primeiros } & \text { socorros } & \text { na } \\
\text { escola: } & \text { construção } & \text { e } \\
\text { validação } & \text { de cartilha } \\
\text { educativa para professores }\end{array}$ & $\begin{array}{l}\text { Construir e validar uma } \\
\text { cartilha educativa para } \\
\text { professores da educação } \\
\text { infantil e ensino } \\
\text { fundamental I sobre } \\
\text { primeiros socorros na } \\
\text { escola. }\end{array}$ & 2017 & $\begin{array}{l}\text { Acta Paul } \\
\text { Enferm }\end{array}$ \\
\hline \begin{tabular}{l}
\multicolumn{1}{c}{ A7 } \\
Silva, LGS; Costa, \\
JB; Furtado, LGS; \\
Tavares, JB; Costa, \\
JLD.
\end{tabular} & 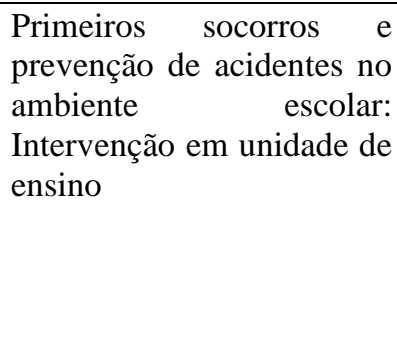 & $\begin{array}{l}\begin{array}{l}\text { Descrever } \\
\text { educativa }\end{array} \\
\text { professores do ensino } \\
\text { primário e identificar } \\
\text { possíveis situações de } \\
\text { risco para acidentes. }\end{array}$ & 2017 & $\begin{array}{c}\text { Enferm. } \\
\text { Foco }\end{array}$ \\
\hline \begin{tabular}{ll}
\multicolumn{2}{c}{ A8 } \\
Grimaldi, & MRM; \\
Gonçalves, & LMS; \\
Melo, ACOS; & Melo, \\
FI; Aguiar, ASC; & Lima, MMN.
\end{tabular} & $\begin{array}{l}\text { A escola como espaço para } \\
\text { aprendizado } \\
\text { primeiros socorros }\end{array}$ & $\begin{array}{l}\text { Programar estratégia } \\
\text { educativa sobre noções } \\
\text { básicas de primeiros } \\
\text { socorros com estudantes } \\
\text { de escola pública e } \\
\text { particular e verificar o } \\
\text { conhecimento destes } \\
\text { antes e após a intervenção } \\
\text { educativa. }\end{array}$ & 2020 & $\begin{array}{c}\text { Revista de } \\
\text { Enfermagem } \\
\text { da UFSM }\end{array}$ \\
\hline
\end{tabular}

Fonte: Esquematizado pelos autores

O Iramuteq 7.2 é capaz de associar diretamente os textos do banco de dados com as variáveis pré-determinadas pelo seu usuário, assim, é possível analisar a produção textual em função dessas variáveis. Esta análise configura-se análise de contrastes em que o corpus é dividido em função da variável escolhida pelo usuário (LAHLOU, 2012; RATINAUD \& MARCHAND, 2012).

É possível comparar a produção textual entre textos em relação a determinado tema, o que foi realizado a partir do resumo dos 8 artigos selecionado. Vejamos: 


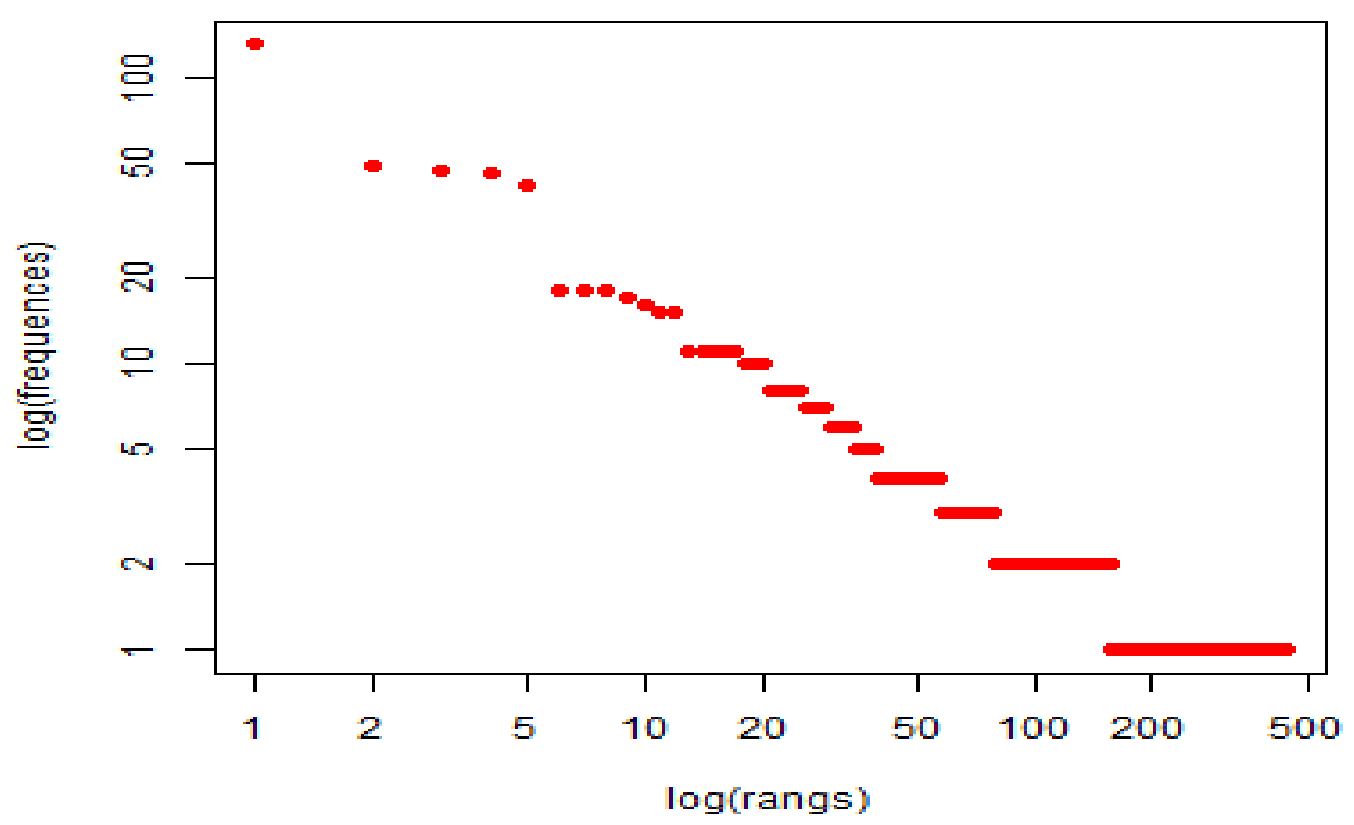

Figura 1- Diagrama de Zipf

Fonte: IRAMUTEQ (2021)

Para análise do log de frequência foram analisados os 8 (oito) artigos, com o total de 1217 ocorrências, 3442 números de formas e 286 números, hápax (23,50\% de ocorrências $64,71 \%$ de formas) com média de ocorrência por texto foi de 152.12 .

\begin{tabular}{|c|c|c|c|c|c|c|c|c|c|}
\hline \multirow{2}{*}{$\begin{array}{l}\text { Formas } X \\
\text { formes }\end{array}$} & \multirow[t]{2}{*}{ Formas comuns } & \multirow{2}{*}{$\begin{array}{l}\text { Tipos } \\
{ }^{*} \text { resu... }\end{array}$} & Forms frequencies & \multicolumn{2}{|c|}{ Tipos de frequências } & \multicolumn{2}{|c|}{ Frequência relativa das formas } & \multicolumn{2}{|c|}{ Tipos de frequências relativas } \\
\hline & & & ${ }^{*}$ resumo2 & *resumo3 & ${ }^{\star}$ resumo4 & ${ }^{\star}$ resumo5 & *resumo6 & *resumo7 & *resumo8 \\
\hline resultado & & 0.6325 & 0.6325 & -0.1828 & $-0,3038$ & -0.1476 & $-0,3961$ & 0.2293 & $-0,3038$ \\
\hline professor & & 0.5662 & -0.5045 & 1.6473 & -0.9006 & -0.5811 & 0.936 & 0.2023 & -0.9006 \\
\hline socorro & & 0.2695 & 0.2695 & 0.8738 & -0.3903 & 0.5363 & -0.2566 & -0.7442 & $-0,3903$ \\
\hline utilizar & & 0.1876 & 0.6325 & -0.5943 & 0.2983 & -0.5241 & 0.2231 & 0.2293 & 0.2983 \\
\hline escola & & -0.5045 & -0.1376 & -0.659 & 0.2509 & -0.1756 & -0.177 & 0.2023 & 1.1654 \\
\hline educativo & & -0.7109 & -0.7109 & -0.9292 & 1.256 & 0.7136 & -0.3653 & 0.4628 & 0.3501 \\
\hline
\end{tabular}

Figura 2- Formas (palavras) evidenciadas nos resumos por frequências

Fonte: Software Iramuteq 7.2

As formas encontradas foram: resultado, professor, socorro, utilizar, escola, educativo. Contudo, essas formas foram possíveis para prosseguirmos, a análise de Classificação Hierárquica Descendente (CHD), o qual possibilita três escolhas diferentes junto ao Iramuteq; e foi utilizada o Simple SUR Textes - que realiza a análise considerando os textos sem dividilos em segmentos de texto, recomendado para respostas mais curtas, utilizado neste estudo. 
Dendrogramme CHD1 - phylogram
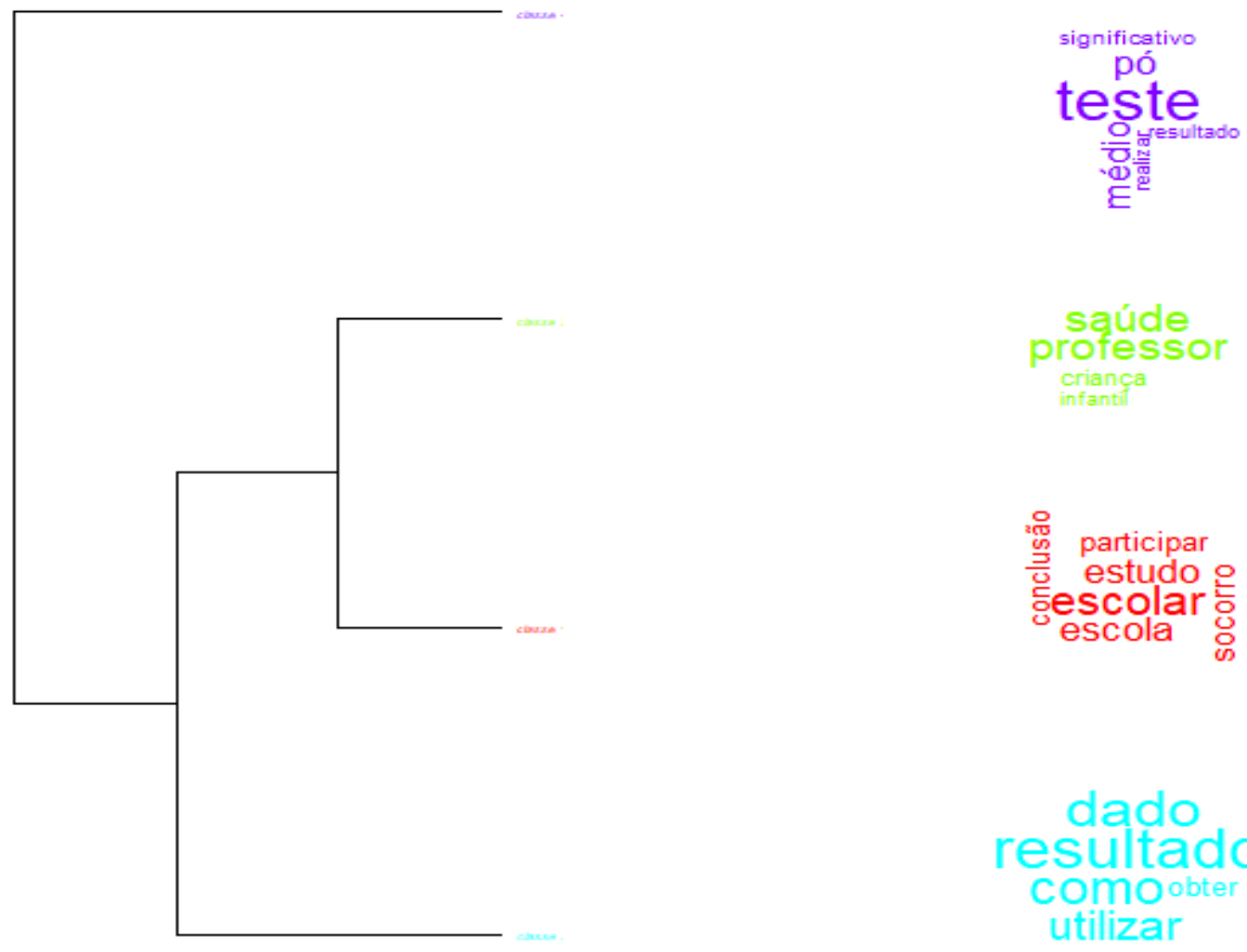

criança

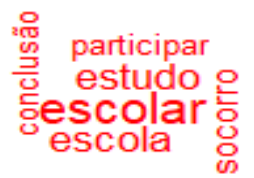

Dendrogramme CHD1 - phylogram

Figura 3- Dendograma II CHD

Fonte: Software Iramuteq 7.2

A figura 3 que demonstra a posição do CHD1 foi desenvolvida e permitiu a produção de registros, gerou palavras de registro por classe 1: Educativo, escolar, estudo; classe 2: Educação, professor, saúde; classe 3: Resultado, base, e finalmente a classe 4: teste, pó, de "pós e após". Destacou-se duas categorias percebidas pelos pesquisadores; mostrada a seguir: Classe 1 e 2 a interação de unidade de registro com significados entre o processo referente saúde e educação; e com aproximação mediana a classe 3 que é a apuração da junção da classe 1 e 2 onde evidencia o resultado e obtenção de dados e por fim, a classe 4 que demostra a características complementares da dinâmica das três primeiras classes.

A representação em nuvem de palavras evidenciou pelo agrupamento e organização lexical em função da frequência dessas palavras, trata-se de uma análise lexical mais simples, entretanto, com uma ilustração gráfica que permite com facilidade e rapidez a identificação das palavras-chave de um corpus.

A partir da análise obtida através desta revisão integrativa, observamos o déficit de conhecimentos básicos acerca dos primeiros socorros, que é percebido tanto dos profissionais 
de escolas públicas, assim como os alunos que frequentam estas unidades de ensino. Também podemos observar quando analisamos os resultados do estudo A1, que os profissionais possuem real interesse nas qualificações sobre o tema, e a efetividade de uma intervenção é de grande significância para as instituições, pois a absorção do conhecimento repassado é positiva.

Portanto, todos os estudos apresentam impactos positivos com a implantação de primeiros socorros em todas as faces de ensino, sejam elas em forma de cursos, cartilhas, atividades lúdicas e educativas.

As escolas necessitam de uma atividade educacional para o tema com devida periodicidade como exposto no estudo A2, demonstrando uma redução de agravos ocorridos nas dependências das escolas avaliadas após o início desses cursos aplicados.

Salientamos também com base no estudo A3, que as escolas necessitam de materiais adequados para prestar uma assistência mais segura. Já no estudo A4, intui que a utilização de um recurso educativo, contribuiu imensamente para o processo de aprendizagem das crianças e adolescentes.

Analisando o estudo A5, podemos observar que os profissionais da equipe técnica não tinham conhecimento suficiente sobre primeiros socorros e a importância da inserção do enfermeiro no ambiente escolar.

O estudo A6 introduz no âmbito escolar a utilização de cartilha como método de ensino com o apoio dos professores. Corroborando, com as medidas educativas que envolvam diálogo, assim como evidencia o estudo $\mathrm{A} 7$, fortalece a prática preventiva e interventiva na escola, perfazendo assim um ambiente ais seguro. E finalmente, a identificação da obtenção de maior resultado de acordo com o estudo A8, foi a implantação da disciplina de primeiros socorros nas escolas.

Finalizando, após a realização da pesquisa foi elaborada um folder virtual intitulado: "Primeiro Socorros nas Escolas: um aprendizado que salva vidas", contendo as informações sobre o conceito de primeiros socorros e acidentes, o que é preciso informar e ligar para Serviço de Atendimento Móvel- 192 (Apêndice I).

\section{CONSIDERAÇÕES FINAIS}

O objetivo proposto de identificarmos estudos evidenciam que os aspectos sobre a necessidade de ensino de primeiros socorros nas escolas públicas, pois a orientação de profissionais é fator determinante para a diminuição dos casos de acidentes dentro das unidades de ensino. A qualificação destes promove também o segundo fator que é a pratica de promoção 
e prevenção de agravos. Uma vez que se tem um funcionário capacitado, o mesmo consegue observar sinais de alerta para determinados fatores de risco facilitando assim a eliminação destes antes mesmo que ocorra algum acidente com alunos da instituição.

Concluímos também, que ainda existem poucos estudos acerca deste assunto, no qual é de suma importância e que necessita de maior visualização pelos profissionais de saúde e dos poderes públicos com o fim de reduzir as morbimortalidades ocorridas na infância no âmbito escolar.

Face exposto assim o intuito de dar seguimento a pesquisas acerca deste tema, com interesses em abrir espaço para mais realizações no campo de escolas de nível fundamental público do nosso país, no enfoque no município de Boa Vista-Roraima-Brasil.

\section{REFERÊNCIA}

ABRAMET, Associação Brasileira de Medicina de Tráfego. Noções de Primeiros Socorros no Trânsito. São Paulo, 2005. Disponível em:<http://www.abramet.portal.provisorio.ws/ conteudos/publicacoes/cartilha_nocoes_de_primeiro s_socorros_no_transito/>.

BARDIN, L. (1997). Análise de conteúdo. Lisboa: Edições 70, 1997.

BRASIL (1940). Código Penal. Decreto-Lei 2.848, de 07 de dezembro de 1940. Disponível em <https://www2.camara.leg.br/legin/fed/declei/1940-1949/decreto-lei-2848-7-dezembro1940-412868- publicacaooriginal-1-pe.html\&gt;.>

BRASIL (2018). Lei n. ${ }^{\circ}$ 13.722, de 4 de outubro de 2018. Torna obrigatória a capacitação em noções básicas de primeiros socorros de professores e funcionários de estabelecimentos de ensino públicos e privados de educação básica e de estabelecimentos de recreação infantil. Disponível em <http://www.planalto.gov.br/ccivil_03/_ato2015-2018/2018/lei/L13722.htm>

BRASIL, Ministério da Saúde (2003). Manual de Primeiros Socorros. Rio de Janeiro: Fundação Oswaldo Cruz, 2003.

BRITO, J.G.; SILVA, I.M.; GODOY C.B., FRANÇA; A.P.S.J.M. Avaliação de treinamento sobre primeiros socorros para equipe técnica de escolas de ensino especializado. Cogitare enferm ; 24: e60340, 2019. tab.

ESCOLAS públicas e particulares de Boa Vista. Escolas.inf.br. Disponível em: $<$ http://www.escolas.inf.br/rr/boa-vista $>$.

FARIA, W.A.; B.F.F.; SILVA, M.A.; SANTOS, R.C.; PENA, H.P. (2020). Primeiros socorros para professores em âmbito escolar: Revisão integrativa. Nursing (Säo Paulo) ; 23(267): 45224528, ago.-2020. 
FARIAS, G.M. GOIS, C.N.A; PINHEIRO, R.O.; SOUTO, J.L.S. (2004). Conhecimento dos professores sobre o atendimento de urgência no recinto escolar análise em duas escolas da grande Natal, RN. XX Encontro de Enfermagem do Nordeste e IV Seminário de Pesquisa da René In.: BARROS, W.C.T.S; FARIAS, G.M.; GOMES, I.B.; MINEIRO, F.H.G.R, RAMOS, C.S (2010). Acidentes em crianças no ambiente escolar: estudo bibliográfico. Disponível em:<http://ww.fiepbulletin.net/index.php/fiepbulletin/article/download/1583/3079\#: :text=A $\% 20$ literatura $\% 20$ mostra $\% 20$ que $\% 20$ grande,de $\% 20$ quedas $\% 20$ durante $\% 20$ outras $\% 20$ atividad es. $>$.

GRIMALDI, M.R.M; GONÇALVES, L.M.S; MELO, A.C.O.S; MELO, F.I; AGUIAR, A.S.C; LIMA, M.M.N. (2020). A escola como espaço para aprendizado sobre primeiros socorros. Rev. enferm. UFSM ; 10: 20, 2020.

LIBERAL, E.F.; AIRES, R.T.; AIRES, M.T.; OSÓRIO, A.C.A ESCOLA SEGURA, NOVEMBRO DE 2005.

MACEDO, P. O. et al. As tecnologias de cuidado de enfermagem obstétrica fundamentadas pela teoria ambientalista de Florence Nightingale. Esc. Anna Nery, Rio de Janeiro, v. 12, n. 2, p. 341-347. 2008.

MANZINI, F. C; SIMONETTI, J. P. Consulta de enfermagem aplicada a clientes portadores de hipertensão arterial: uso da teoria do autocuidado de Orem. Revista Latino-Americana de Enfermagem. 2009.

MEDEIROS, A.B.A; ENDERS, B. C; LIRA, A. L. B.C. Teoria Ambientalista de Florence Nightingale: Uma Análise Crítica. Esc. Anna Nery, Rio de Janeiro, v. 19, n. 3, p. 518524. 2015.

MESQUITA, T.M.; ALBUQUERQUE, R.S.; BOMFIM, A.M.A.; SALES, M.L.H.; SANTANA, M.C.C.P.; FERREIRA, A.M.V. (2017). Recurso educativo em primeiros socorros no processo ensino-aprendizagem em crianças de uma escola pública. Rev. Ciênc. Plur ; 3(1): 35-50, 2017. tab, graf

NETO, N.M.G.; CAETANO, J.A.; BARROS, L.M.; SILVA, T.M.; VASCONCELOS, E.M.R. (2017). Primeiros socorros na escola: construção e validação de cartilha educativa para professores. Acta paul. enferm ; 30(1): 87-93, jan.-fev. 2017. tab, graf

OLIVEIRA, R.A. (2008). Comportamentos de risco para acidentes em playgrounds: identificação e opiniões de profissionais da educação infantil. 2008. 167 f. Tese (Doutorado em Educação). Marília: Faculdade De Filosofia e Ciências. Disponível em $<$ https://repositorio.unesp.br/bitstream/handle/11449/102226/oliveira_ra_dr_mar.pdf?sequenc $\mathrm{e}=>$;

PRÉDINE R, CHAU N, LORENTZ N, PRÉDINE E, LEGRAS B, BENAMGHAR L. (2002). Les accidents scolaires dans des établissements d'enseignement general: incidence, causes et consequences. Rev. Épidémiol. Santé Publique. <Disponível em: http://cat.inist.fr/?aModele=afficheN\&amp;cpsidt=13787078> In.: CARMO, H.C. SOUZA, R.C.A., ARAÚJO, C.L.O , FRANCISCO, A.G. (2017) Atitudes dos docentes de educação infantil em situação de acidente escolar. Revista de Enfermagem do Centro. 
RATINAUD, P., \& MARCHAND, P. (2012). Application de la méthode ALCESTE à de "gros" corpus et stabilité des "mondes lexicaux" : analyse du "CableGate" avec IraMuTeQ. Em: Actes des 11eme Journées internationales d'Analyse statistique des Données Textuelles (835-844). Presented at the 11eme Journées internationales d'Analyse statistique des Données Textuelles. JADT 2012.

RODRIGUES, H. G.; RODRIGUES, E. A. F. (2016) Os primeiros socorros na educação física escolar. Revista Científica Multidisciplinar Núcleo do Conhecimento. Ano 1. Vol. 9. pp. 215-234, outubro /novembro de 2016. ISSN. 2448-0959

SENA, S.P.; RICAS, J.; VIANA, M.R.A. (2008). A percepção dos acidentes escolares por educadores do ensino fundamental. Revista Médica de Minas Gerais, Belo Horizonte, MG, v. 18, n.4, s.1, p. 47-54. 2008. Disponível em: Acesso em: 30 de out. de 2020.

SILVA, D.P.; NUNES, J.B.B.; MOREIRA R.T.F. et al. (2018). Primeiros socorros: Objeto de educação em saúde para professores. Rev. enferm. UFPE on line ; 12(5): 1444-1453, maio 2018. ilus, graf, tab

SILVA, L.G.S.; et al. (2017). Primeiros socorros e prevenção de acidentes no ambiente escolar: intervenção em unidade de ensino. Enferm. foco (Brasília) ; 8(3): 25-29, nov.-2018.

SILVANI, C.B; GOMES, G.C. SOUSA, L.D.; SOUSA J.L (2008). Prevenção de acidentes em uma instituição de educação infantil: o conhecimento das cuidadoras. Revista de enfermagem UERJ, Rio de Janeiro, v.16, n.2, p.200-205, abr./jun. 2008.

SOARES, F. (2014). Primeiros Socorros. Instituto Formação. Disponível em: <http://www.ifcursos.com.br/sistema/admin/arquivos/11-51-19-.pdf>. Acesso em: 16 de out. de 2020.

SOUZA, M.F.; DIVINO, A.B.; SOUZA, D.A.S.; CUNHA, S.G.S.; ALMEIDA, C.S. (2020). Conhecimento dos educadores dos centros municipais de educação infantil sobre primeiros socorros. Nursing (Säo Paulo) ; 23(268): 4624-4629, set.2020.

VIDIGAL, S. (2011). Projeto de Lei 1616/2011. Obriga presença de enfermeiro em creches públicas.

Disponível em<https://www.camara.leg.br/proposicoesWeb/fichadetramitacao;jsessionid=A9D4873FC79 3392AA882 8771DA63D2ED.proposicoesWeb2?idProposicao=509421\&amp;ord=0>; 


\title{
Resumem
}

Según el Ministerio de Salud, la asistencia de primeros auxilios puede ser realizada por cualquier persona que tenga conocimientos de técnicas básicas. Objetivo: el propósito de este artículo es identificar la importancia de la orientación de las técnicas de primeros auxilios. Metodología: se trata de una revisión integradora de la literatura, en las bases de datos BVS (Biblioteca Virtual en Salud - Brasil) y LACLHS (Literatura del Caribe Latinoamericano en Ciencias de la Salud), utilizando los criterios de exclusión por descriptores, título, idioma y año de publicación. Resultado: la necesidad de impartir primeros auxilios a los profesionales de las escuelas públicas, porque estos son factores determinantes en la reducción de accidentes, mortalidad, reducción de daños, así como en la promoción precursora y la prevención de la salud, trayendo únicamente beneficios a las unidades que reciben este tipo de capacitación.

Palabras clave: Primeros auxilios, Docencia, Accidentes.

\begin{abstract}
According to the Ministry of Health, first aid assistance can be performed by anyone who has knowledge of basic techniques. Objective: the purpose of this article is to identify the importance of first aid techniques guidance. Methodology: this is an integrative literature review, in the databases VHL (Virtual Health Library - Brazil) and LACLHS (Latin American Caribbean Literature in Health Sciences), using the exclusion criteria by descriptors, title, language and year of publication. Result: the necessity for teaching first aid to professionals of public schools, because these are determining factors in reducing accidents, mortality, damage reduction, as well as promotion precursor and health prevention, bringing only benefits to the units that receive this type of training.
\end{abstract}

Keywords: First aid, Teaching, Accidents. 
Primeiros Socorros Nas Escolas: Uma Revisão Integrativa

\section{APÊNDICE I}

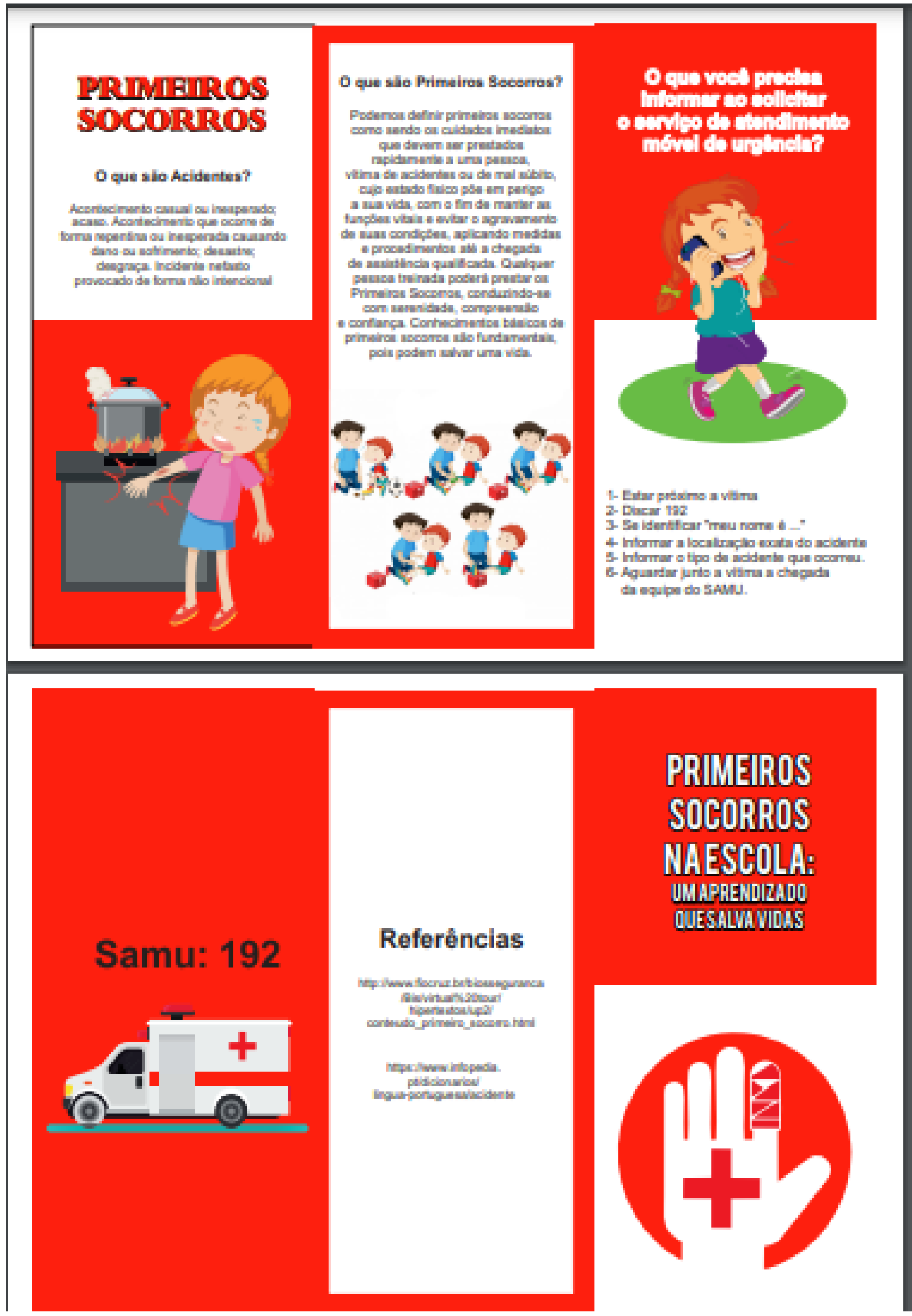

